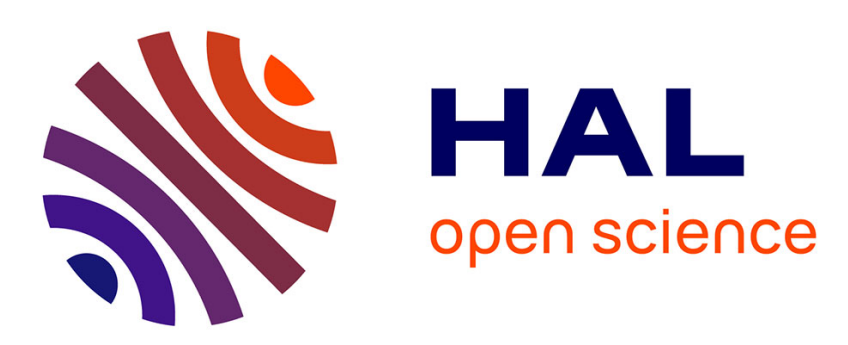

\title{
Modelling of the Mechanism of Formation of Spherical Grains Obtained by the Quasi-Emulsion Crystallization Process
}

Fabienne Espitalier, Béatrice Biscans, J.-R. Authelin, C Laguérie

\section{- To cite this version:}

Fabienne Espitalier, Béatrice Biscans, J.-R. Authelin, C Laguérie. Modelling of the Mechanism of Formation of Spherical Grains Obtained by the Quasi-Emulsion Crystallization Process. Chemical Engineering Research and Design, 1997, 75 (2), pp.257-267. 10.1205/026387697523543 . hal-01868699

\section{HAL Id: hal-01868699 \\ https://hal.science/hal-01868699}

Submitted on 5 Sep 2018

HAL is a multi-disciplinary open access archive for the deposit and dissemination of scientific research documents, whether they are published or not. The documents may come from teaching and research institutions in France or abroad, or from public or private research centers.
L'archive ouverte pluridisciplinaire HAL, est destinée au dépôt et à la diffusion de documents scientifiques de niveau recherche, publiés ou non, émanant des établissements d'enseignement et de recherche français ou étrangers, des laboratoires publics ou privés. 


\title{
MODELLING OF THE MECHANISM OF FORMATION OF SPHERICAL GRAINS OBTAINED BY THE QUASI-EMULSION CRYSTALLIZATION PROCESS
}

\author{
F. ESPITALIER*, B. BISCANS*, J-R. AUTHELIN** and C. LAGUERIE* \\ *Laboratoire de Génie Chimique UMR CNRS 5503, ENSIGC, Toulouse, France \\ **Rhône-Poulenc Rorer, centre de Recherche de Vitry Alfortville, Vitry-sur Seine, France
}

\begin{abstract}
I $\mathrm{n}$ order to improve particle properties, new processes combining granulation and crystallization are being developed. This present work deals with the spherical crystallization process by the quasi-emulsion mechanism applied to a pharmaceutical drug, ketoprofen. The different steps occurring in the process are first the formation of an $\mathrm{O} / \mathrm{W}$ emulsion, then the creation of the supersaturation of drug into the droplets by mass transfer and heat transfer, and finally the nucleation, growth and agglomeration of drug crystals inside the droplets. The mechanism of formation has been modelled in order to aid control of the size, shape and internal structure of grains as a function of the droplet size.
\end{abstract}

Keywords: spherical crystallization; emulsion droplets; mass transfer; thermal transfer; modelling

\section{INTRODUCTION}

In order to improve pharmaceutical particle properties, such as flowability, packability and compressibility, spherical crystallization processes combining granulation and crystallization are being developed. These processes allow production in one step of spherical grains made of small agglomerated crystals of the drug. Direct tabletting of these particles is possible without further processing (mixing, agglomeration etc.) because the micromeritic properties of the pharmaceutical drug can be sufficiently improved by the spherical crystallization process ${ }^{1,2}$. Control of these properties thus enables control of the tabletting. This paper deals with the process of spherical crystallization by the quasi-emulsion mechanism or the emulsion solvent diffusion process ${ }^{3}$.

In spherical crystallization, the choice of the solvents is one of the main steps. Our system is composed of a pharmaceutical drug, ketoprofen (alpha-(3-benzoylphenyl)-propionic acid), a good solvent of ketoprofen, acetone and a poor solvent of ketoprofen, water. The ternary phase diagrams of this system (ketoprofen+ acetone + water) at various temperatures have been presented elsewhere ${ }^{4}$. The solubility diagram exhibits five regions : one homogeneous liquid zone, three twophase zones (two liquid-solid and one liquid-liquid equilibria) and one three-phase zone. In the liquid-solid regions, the solubility of ketoprofen increases with temperature. An acetone mass ratio in acetone + water mixture, $R_{\mathrm{a}}$, which delimits the different regions of the phase diagram, has been defined. For low $R_{\mathrm{a}}$, the solubility of the drug increases with this mass ratio. Liquid-liquid zones are obtained for $R_{\mathrm{a}}$ in the range $R_{\mathrm{a}, 1}$ and $R_{\mathrm{a}, 2}$. When $R_{\mathrm{a}}$ is higher than $R_{\mathrm{a}, 2}$, the solubility reaches a maximum for a value between 0.86 and $0.93 \mathrm{~kg}$ acetone $/ \mathrm{kg}$ acetone + water mixture. At $20^{\circ} \mathrm{C}$, the mass ratio $R_{\mathrm{a}, 1}$ and $R_{\mathrm{a}, 2}$ are respectively equal to 0.24 and 0.67 $\mathrm{kg}$ acetone $/ \mathrm{kg}$ acetone + water mixture.

The ternary system (ketoprofen + acetone + water) described by this phase diagram is present within the droplets.

The principle of the process is based on the preparation of acetone saturated with ketoprofen at $50^{\circ} \mathrm{C}$ and dispersion of this hot solution in aqueous solution, producing quasi-emulsion droplets.

A polyvinylic alcohol, mowiol $8-88$, is added to the water in order to improve the dispersion of acetone + ketoprofen solution. The mass fraction of mowiol in continuous phase generally used is $223 \times 10^{-6} \mathrm{~kg}$ mowiol $/ \mathrm{kg}$ water. It was shown that this emulsifier does not move inside the droplets during the experiment ${ }^{3}$.

The continuous phase has a temperature $T 2$ lower than $50^{\circ} \mathrm{C}$ and is contained in a stirred vessel. As soon as the emulsion droplets are formed due to the presence of the emulsifier, water and acetone diffuse countercurrently through the droplets. Heat and mass transfer phenomena lead the droplet to a limit supersaturation state allowing crystallization of ketoprofen.

So the different steps occurring in the process are first, the formation of an emulsion, then, the creation of the supersaturation of ketoprofen into the droplets by mass transfer and heat transfer, and finally, the nucleation, growth and agglomeration of ketoprofen crystals inside the droplets. Three types of internal structure of the solid grains have been identified and explained in a previous work: grains with one crust at their periphery, grains with two juxtaposed crusts and grains full of crystals ${ }^{5}$. The different steps and structures are summarized in 


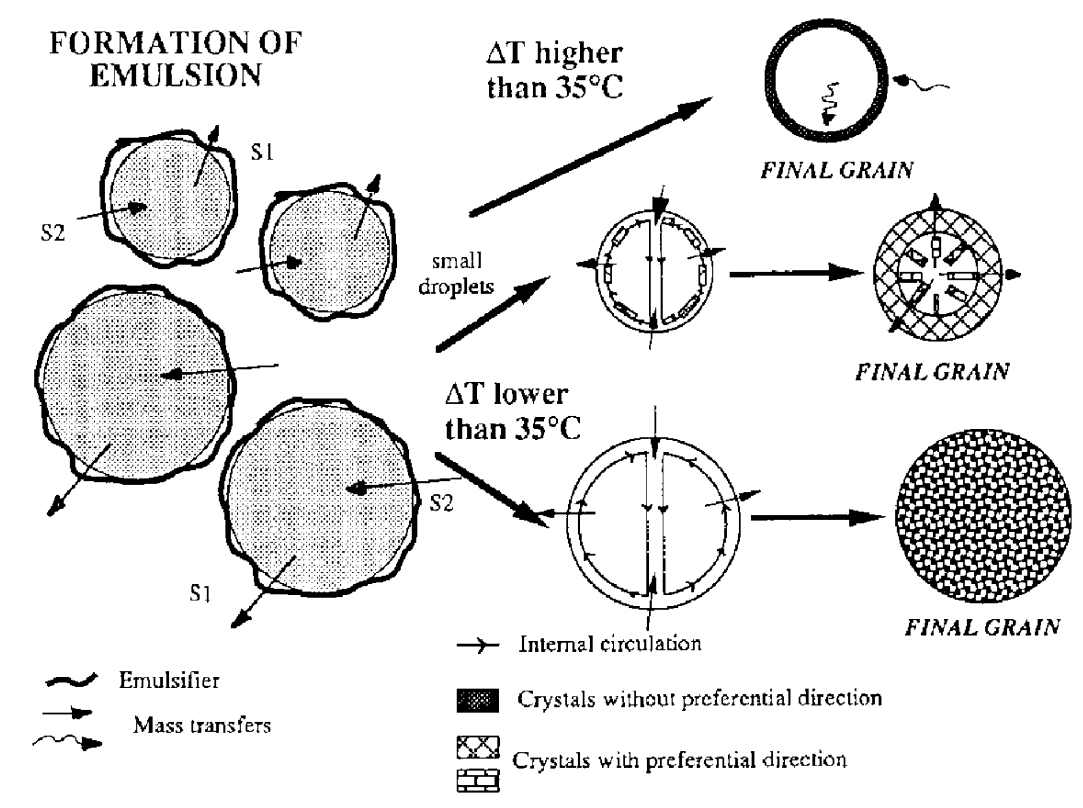

Figure 1. Mechanism of formation of spherical grains by the quasi-emulsion process.

Figure 1. The size, shape and internal structure of grains depend on the initial size of the droplets.

This work deals with modelling the mechanism of grain formation by the quasi-emulsion process. In the first part, the creation of droplets is analysed. The different phenomena occurring inside the droplet are treated separately in the second part. Finally, the modelling of mass transfers in the droplet is presented.

\section{INITIAL SIZE OF DROPLETS}

The size of droplets depends on mass transfer and emulsifier concentrations at interface droplet/continuous phase $^{6}$. In addition, in this case, the initial size of the droplets changes with the external hydrodynamics of the system (stirring rate, flowrate of poured solution), and the volume ratio of the dispersed phase.

It is well known that in this type of emulsion, the intensity of the internal circulations inside the droplets depends on the size of the droplets. In the presence of emulsifier, for small droplets, these circulations become negligible ('rigid droplet') 6 .

So, initially, for given operating conditions, the crystallizer contains droplets with internal circulations and small droplets without circulations. Two limiting cases have been modelled:

- the formation of spherical grains derived from droplets with internal circulations,

- the formation of spherical grains derived from droplets without internal circulations.

The first model is called the homogeneous droplet model, with reference to the formation of full grains, while the second model is called the rigid droplet model because it leads to the formation of grains with a crust.

\section{LIMITING PHENOMENA AND CRITICAL SIZE}

Mass transfer, heat transfer and internal circulations are in competition in the droplets initially formed. These phenomena are described by the usual balance equations? The following development aims to show the limiting phenomena and to justify the chosen assumptions for modelling.

\section{Thermal Transfer}

Assuming that the thermal transfer is independent of mass transfer, internal circulations and crystallization, the temperature profiles inside the droplets surrounded by a stagnant aqueous phase, at temperature $T 2$, with negligible convection can be obtained by the resolution of the thermal energy equation in a spherical coordinate system $^{7}$. By applying the boundary conditions $r=R_{\mathrm{g}}$, $T=T 2$ and initial condition $t=0, T=T 1$ for all $r\left(0 \leq r<R_{\mathrm{g}}\right)$, it can be shown that the thermal penetration distance, $\delta_{\mathrm{T}}$, increases as

$$
\delta_{\mathrm{T}} \approx \sqrt{\pi^{\alpha^{\mathrm{m}} t}}
$$

where $\alpha^{\mathrm{m}}\left(=\frac{\lambda^{\mathrm{m}}}{\rho^{\mathrm{m}} \cdot \mathrm{c}_{\mathrm{m}} \mathrm{m}}\right)$ is the thermal diffusivity of the acetone + ketoprofen mixture. Thus the characteristic time for conductive transport to depth $r$ is $t \approx \mathrm{r}^{2} /\left(\pi \alpha^{\mathrm{m}}\right)$.

In order to calculate the thermal diffusivity, a linear composition law has been used. A mean thermal diffusivity equal to $7.3 \times 10^{-5} \mathrm{~m}^{2} \mathrm{~s}^{-1}$ has been found between 10 and $50^{\circ} \mathrm{C}$. The ketoprofen concentration has been chosen equal to the saturation concentration at $50^{\circ} \mathrm{C}(T 1)$, i.e. 0.660 ketoprofen $/ \mathrm{kg}$ solution.

So, in the cases where $r=100 \mu \mathrm{m}, 200 \mu \mathrm{m}, 300 \mu \mathrm{m}$, and $\alpha=7.3 \times 10^{-5} \mathrm{~m}^{2} \mathrm{~s}^{-1}$, the characteristic times are respectively $4.3 \times 10^{-5}, 1.7 \times 10^{-4}$ and $3.9 \times 10^{-4} \mathrm{~s}$. So, the thermal transfer inside a droplet immersed into a stagnant continuous phase is assumed to be quasi-instantaneous.

On the other hand, for mass transport with a diffusion coefficient about $10^{-9} \mathrm{~m}^{2} \mathrm{~s}^{-1}$, this calculation leads to a characteristic time of $12 \mathrm{~s}$ for a droplet with $r=200 \mu \mathrm{m}$. This result suggests that the mass diffusion is limiting.

\section{Internal Circulation}

Internal circulation can be calculated from momentum balance and continuity equations in accordance with the terminal velocity. Mass and heat transfer and traces of 
surface-active contaminants may have a profound effect on the behaviour of droplets. Even though the amount of impurity may be so small that there is no measurable change in bulk properties, a contaminant can eliminate internal circulation, thereby drastically reducing overall mass and heat transfer. Surface contaminants affect mass transfer via hydrodynamics and molecular effects ${ }^{6}$.

The terminal velocity of a rigid sphere in creeping flow is obtained by the following equation:

$$
U^{\infty}=\frac{\Delta \rho g d_{\mathrm{g}}^{2}}{18 \mu}
$$

It is given from Stokes' law for a Reynolds number lower than 2.

The terminal velocity and the corresponding particle Reynolds number have been calculated as a function of droplet size. The difference of densities $\Delta \rho$ has been chosen ${ }^{3}$ equal to $33 \mathrm{~kg} \mathrm{~m}^{-3}$. From these results, as the Reynolds numbers becomes higher than 2 from a droplet with a diameter higher than $450 \mu \mathrm{m}$, it has been assumed that droplets with a diameter lower than $450 \mu \mathrm{m}$ acted as rigid spheres and those with a diameter higher as fluid spheres. Grains created from droplets with a diameter lower than $450 \mu \mathrm{m}$ will thus have a full internal structure and the larger other grains an internal structure with a hole. This limit on the size of droplets seems to agree with the experimental limit on the size of grains.

\section{Mass Transfer}

\section{Diffusion coefficients}

Fick's law has been adopted to calculate the diffusional flux:

$$
\vec{J}_{\mathrm{i}}=-D_{\mathrm{im}} C \overline{\operatorname{grad}} x_{\mathrm{i}}
$$

Assuming that the diffusion coefficient $D_{\text {im }}$ is constant, the chosen reference is a system with a fixed molar flux.

In order to calculate the diffusion coefficient of solute $i$ in mixture $m$ (acetone + water + ketoprofen), the following equation has been used:

$$
D_{\mathrm{im}}=\frac{1-x_{\mathrm{i}}}{\sum_{=1}^{3} \frac{x_{\mathrm{j}}}{D_{\mathrm{ij}}}}
$$

$D_{\mathrm{ij}}$ is the diffusion coefficient of component $i$ in the solvent $j$. Two coefficients have been calculated: the diffusion coefficient of acetone in the mixture and of water in the mixture. The details of the calculation are given in Appendix 1. The diffusion coefficient of acetone in acetone + ketoprofen and the diffusion coefficient of water in acetone + ketoprofen at $20^{\circ} \mathrm{C}$ are respectively equal to $0.19 \times 10^{-9}$ and $1.83 \times 10^{-9} \mathrm{~m}^{2} \mathrm{~s}^{-1}$.

\section{Mass transfer coefficient:}

The surface polymer can be considered like a interfacial film. The flux at the interface of the film is calculated according to the equation:

$$
N_{\mathrm{j}}^{\mathrm{film}}=\frac{D_{\mathrm{j}}^{\mathrm{film}}}{e^{\text {film }}}\left(C_{\mathrm{j}}^{\mathrm{d}, \text { film }}-C_{\mathrm{j}}^{\mathrm{c}, \text { film }}\right)
$$

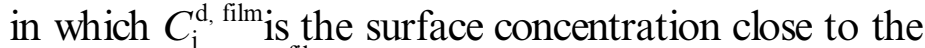
droplet and $C_{\mathrm{j}}^{\mathrm{c} \text {, film }}$ is the concentration close to the continuous phase. It is assumed that at the interfaces droplet/polymer and polymer/continuous phase, equilibrium is reached and that there is no interfacial resistance to mass transfer. The equation relates the concentrations on each side of the interfaces :

$$
\begin{aligned}
& C_{\mathrm{j}}^{\mathrm{d}, \text { film }}=\kappa_{\mathrm{j}}^{1} C_{\mathrm{j}}^{\mathrm{d}}\left(R_{\mathrm{g}}\right) \\
& C_{\mathrm{j}}^{\mathrm{c}, \text { film }}=\kappa_{\mathrm{j}}^{2} C_{\mathrm{j}}^{\infty}
\end{aligned}
$$

where $\kappa_{\mathrm{j}}^{1}$ and $\kappa_{\mathrm{j}}^{2}$ are respectively the equilibrium ratios between the dispersed phase/emulsifier and emulsifier/ continuous phase. So equation (5) can be written :

$$
N_{\mathrm{j}}^{\text {film }}=k_{\mathrm{j}}\left(C_{\mathrm{j}}^{\mathrm{d}}-m^{\mathrm{j}} C_{\mathrm{j}}^{\infty}\right)
$$

where $k_{\mathrm{j}}$ and $m^{\mathrm{j}}$ are respectively equal to

$$
\begin{aligned}
& \frac{D_{\mathrm{j}}^{\mathrm{film}}}{e^{\mathrm{film}} \kappa_{\mathrm{j}}^{1}} \text { and } \frac{\kappa_{\mathrm{j}}^{2}}{\kappa_{\mathrm{j}}^{1}} \\
& N_{\mathrm{j}}^{\mathrm{film}}=N_{\mathrm{j}}^{\mathrm{d}}=N_{\mathrm{j}}^{\mathrm{c}}
\end{aligned}
$$

$k_{\mathrm{j}}$ and $m^{\mathrm{j}}$ have been calculated from experimental transfer curves giving the concentration of acetone in the continuous phase versus time. The operating conditions of these experiments are given in Appendix 2. The transfer curves were presented in a previous work ${ }^{8}$. For the calculations, the following assumptions have been made:

- the volume of the dispersed phase, the volume of the continuous phase and the number of droplets are constant with time and the additivity of components volume is used.

the mean diameter of the size distribution is constant during the transfer and is equal to the mean volume diameter of the final grains.

The results are reported in Tables 1, 2 and 3.

Mass transfer coefficients of acetone and water increase when the mass of ratio of acetone/water increases. The increase of these ratios is linked with the volume ratio of dispersed phase in the crystallizer; so the thickness of the emulsifier film at the surface of the droplets decreases when the acetone/water ratio increases. This decrease of thickness explains the increases of mass transfer coefficients $k_{\mathrm{a}}$ and $k_{\mathrm{w}}$. However, the mass transfer coefficients do not depend on the initial concentration of ketoprofen into the droplets.

\section{Penetration of water into the droplets:}

The mass transfer of water in a droplet, diameter equal to $200 \mu \mathrm{m}$, is here considered. This droplet contains a mixture of acetone and ketoprofen saturated at $50^{\circ} \mathrm{C}$. The temperature of the droplet is assumed constant and equal to $20^{\circ} \mathrm{C}$. Assuming constant $\rho$ and $D_{\text {wm }}$, the continuity equation for water becomes:

$$
\frac{\partial C_{\mathrm{w}}}{\partial t}+\left(v \cdot \nabla C_{\mathrm{W}}\right)=D_{\mathrm{wm}} \nabla^{2} C_{\mathrm{w}}+R_{\mathrm{w}}
$$

If there are no chemical changes occurring, $R_{\mathrm{w}}$ is zero. If, 
Table 1. $m^{\mathrm{a}}$ and $m^{\mathrm{w}}$ and mass transfer coefficients in accordance with ratio acetone-water.

\begin{tabular}{lcccccc}
\hline experiment & $\begin{array}{c}A / E \\
\text { (kg acetone/ } \\
\text { kg water) }\end{array}$ & $d_{32}(\mu \mathrm{m})$ & $m^{\mathrm{a}}$ & $\begin{array}{c}k_{\mathrm{a}} \times 10^{6} \\
\left(\mathrm{~ms}^{-1}\right)\end{array}$ & $\mathrm{m}^{\mathrm{w}}$ & $\begin{array}{c}k_{\mathrm{w}} \times 10^{7} \\
\left(\mathrm{~ms}^{-1}\right)\end{array}$ \\
\hline & & & & & & \\
1 & 0.026 & 160 & 13 & 8.5 & 0.7 & 2.2 \\
2 & 0.054 & 192 & 5.1 & 22.2 & 0.8 & 15.1 \\
3 & 0.078 & 319 & 2.9 & 41.4 & 0.8 & 45.9 \\
\hline
\end{tabular}

Table 2. $m^{\mathrm{a}}$ and $m^{\mathrm{w}}$ and mass transfer coefficients in accordance with ratio ketoprofen-acetone.

\begin{tabular}{lcccccc}
\hline experiment & $\begin{array}{c}K / A(\mathrm{~kg} \\
\text { ketoprofen } / \\
\mathrm{kg} \text { acetone })\end{array}$ & $\mathrm{d}_{32}(\mu \mathrm{m})$ & $\mathrm{m}^{\mathrm{a}}$ & $\begin{array}{c}k_{\mathrm{a}} \times 10^{6} \\
\left(\mathrm{~ms}^{-1}\right)\end{array}$ & $m^{\mathrm{w}}$ & $\begin{array}{c}k_{\mathrm{w}} \times 10^{7} \\
\left(\mathrm{~ms}^{-1}\right)\end{array}$ \\
\hline 1 & 1.75 & 160 & 13 & 8.5 & 0.7 & 2.2 \\
4 & 1.01 & 137 & 22 & 8.9 & 0.6 & 1.4 \\
\hline
\end{tabular}

in addition, $v$ is equal to zero, then:

$$
\frac{\partial C_{\mathrm{w}}}{\partial t}=D_{\mathrm{wm}}\left(\frac{\partial^{2} C_{\mathrm{w}}}{\partial r^{2}}+\frac{2}{r} \frac{\partial C_{\mathrm{w}}}{\partial r}\right)
$$

The integration of equation (11) leads to the following relation giving the water concentration, $C_{\mathrm{w}}$, inside the droplets as a function of the droplet radius and time:

$$
\begin{aligned}
\left(C_{\mathrm{W}}(r, t)-C_{\mathrm{W}}^{\mathrm{int}}\right) r= & 2\left(C_{\mathrm{W}}(r, 0)-C_{\mathrm{W}}^{\mathrm{int}}\right) \frac{R_{\mathrm{g}}}{\pi} \\
& \sum_{\mathrm{r}=1}^{\infty} \frac{(-1)^{\mathrm{n}}}{n} \exp \left(-\frac{n^{2} \pi^{2}}{R_{\mathrm{g}}^{2}} D_{\mathrm{wm}} t\right) \\
& \sin \left(\frac{n \pi r}{R_{\mathrm{g}}}\right)
\end{aligned}
$$

with the following initial and boundary conditions:

$$
\begin{array}{lll}
t=0 \quad 0 \leq r<R_{\mathrm{g}} & C_{\mathrm{w}}(r, 0)=0 \\
t>0 & r=0 & \left(\frac{\partial C_{\mathrm{w}}(0, t)}{\partial r}\right)=0 \\
t>0 & r=R_{\mathrm{g}} & C_{\mathrm{w}}\left(R_{\mathrm{g}}, t\right)=C_{\mathrm{w}}^{\mathrm{int}} m^{\mathrm{w}} C_{\mathrm{w}}^{\mathrm{c}} \\
& & =38889 \mathrm{molm}^{-3}
\end{array}
$$

Figures 2 and 3 present respectively the water concentration inside the droplet and relative supersaturation, $\sigma$, as a function of the droplet radius for

Table 3. $m^{\mathrm{a}}$ and $m^{\mathrm{w}}$ in accordance with temperature of continuous phase, $T 2$.

\begin{tabular}{llll}
\hline experiment & $\begin{array}{c}T 2 \\
\left({ }^{\circ} \mathrm{C}\right)\end{array}$ & $m^{\mathrm{a}}$ & $m^{\mathrm{w}}$ \\
\hline 5 & 10.4 & 17 & 0.7 \\
1 & 20.1 & 13 & 0.7 \\
6 & 48.9 & 8 & 1 \\
\hline
\end{tabular}

different times. The relative supersaturation has been calculated at $20^{\circ} \mathrm{C}$ using a preliminary calculation of the solubility of ketoprofen in acetone + water mixtures ${ }^{4}$. Figure 3 shows that the relative supersaturation decreases and then increases when the radius increases, for example after 0.5 second. This variation is caused by the variation of ketoprofen solubility in a mixture of acetone + water as a function of the ratio $R_{\mathrm{a}}{ }^{4}$. When the particular ratio is reached, two liquid phases appear and the curves are interrupted. So, the solid will appear preferably at the interface.

\section{MASS TRANSFER MODELLING ASSUMPTIONS}

According to the previous development, several assumptions can be drawn:

- the heat transfer in a stagnant continuous phase maintained at a constant temperature is quasiinstantaneous. The temperature of droplets is equal to

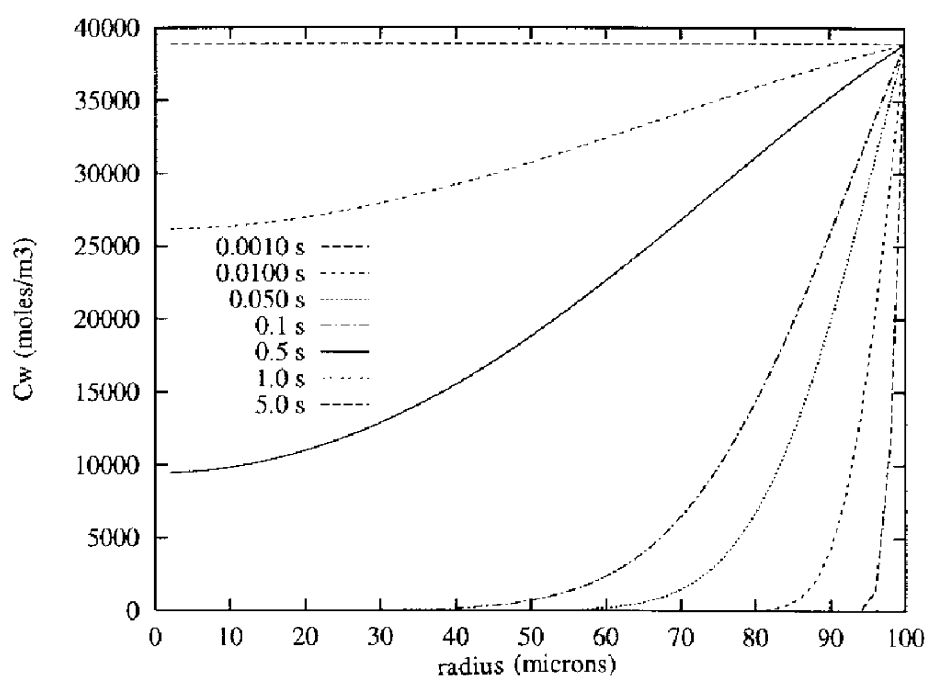

Figure 2. Profile of water concentration into a droplet with a diameter equal to $200 \mu \mathrm{m}$ at $20^{\circ} \mathrm{C}$ in accordance with time $\left(D_{\mathrm{wm}}=1.83 \times 10^{-9} \mathrm{~m}^{2} \mathrm{~s}^{-1}, C_{\mathrm{w}}\left(R_{\mathrm{g}}, t\right)=38889 \mathrm{molm}^{-3}\right)$. 


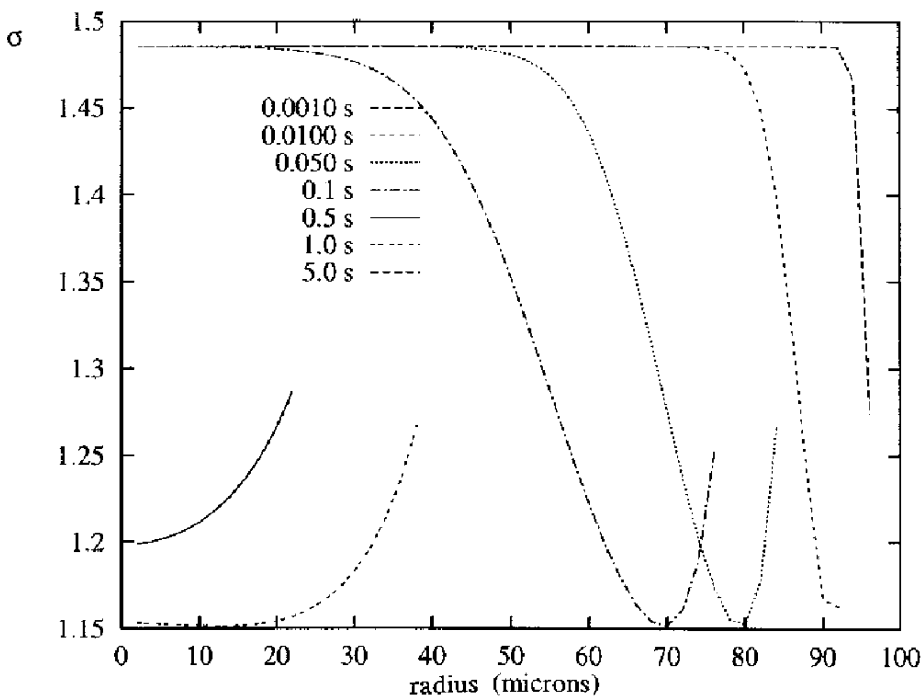

Figure 3. Profile of relative supersaturation into a droplet with a diameter equal to $200 \mu \mathrm{m}$ at $20^{\circ} \mathrm{C}$ in accordance with time $\left(D_{\mathrm{wm}}=1.83 \times 10^{-9} \mathrm{~m}^{2} \mathrm{~s}^{-1}, C_{\mathrm{w}}\left(R_{\mathrm{g}}, t\right)=38889 \mathrm{molm}^{-3}\right)$.

the temperature of the continuous phase in less than $10^{-3}$ second.

- A limiting size, $450 \mu \mathrm{m}$, has been defined from the terminal velocity. Since the mass transfer has a limiting effect, this is the only transport process considered in the modelling of the droplets.

Two models have been developed. The first model (size of droplets $>450 \mu \mathrm{m}$ ), called the 'homogeneous droplet model', considers that internal circulations tend to homogenize the concentrations of the different components in the droplets. The second model (valid for droplets $<450 \mu \mathrm{m})$, called the 'rigid droplet model', assumes that internal circulations are negligible inside the droplets.

The assumptions of these two model are set out in Table 4.

At the interface, the fluxes of acetone and water are calculated from equations (8) and (9). The flux of ketoprofen is assumed equal to zero. The initial compositions into the droplet and in the continuous phase are homogeneous.

The two models are divided into two parts. In the first step, the droplet remains liquid as long as the mass ratio
$R_{\mathrm{a}}$ is higher than the particular ratio $R_{\mathrm{a}, 2}$. Only mass transfer modifies the concentration or mass fraction into the droplets during the time interval $\mathrm{d} t$. In the second step $\left(R_{\mathrm{a}}<R_{\mathrm{a}, 2}\right)$, two phases appears in the droplet and ketoprofen crystallizes.

In the 'homogeneous droplet model', the solid appears in all volumes of the droplet. Knowing the saturated concentration for a ratio $R_{\mathrm{a}}$ (ternary diagram), the mass of ketoprofen that has to crystallize to reach the equilibrium of the system inside the droplet can be estimated. If the solution into the droplet is undersaturated, the crystallized ketoprofen is redissolved in order to maintain the equilibrium. When the ratio $R_{\mathrm{a}}$ is lower than $R_{\mathrm{a}, 1}$, the organic liquid phase (acetone + ketoprofen) disappears into the droplet and then the mass fluxes of acetone and water are equal to zero.

In the 'rigid droplet model', the droplets are divided into different concentric layers. Equations of mass transfer have been written in each layer and in the continuous phase. The solution of the equations has been obtained in the case of droplets with variable radius. When ketoprofen crystallizes near to the interface, the interfacial fluxes of acetone and water are equal to zero. So the grain volume is constant.

\section{MASS TRANSFER MODELLING IN HOMOGENEOUS DROPLETS Equations}

Ketoprofen remains in droplets. So, the variations of ketoprofen moles dissolved are equal to the variations of ketoprofen moles crystallized in the droplets.

$$
\frac{\mathrm{d} n_{\mathrm{k}}^{\mathrm{d}}}{\mathrm{d} t}=-\frac{\mathrm{d} n_{\mathrm{k}}^{\mathrm{d}, \mathrm{s}}}{\mathrm{d} t}
$$

The balances on acetone and water are expressed by the following equations:

$$
\begin{aligned}
& \frac{\mathrm{d} n_{\mathrm{a}}^{\infty}}{\mathrm{dt}}=-n_{\mathrm{g}} \frac{\mathrm{d} n_{\mathrm{a}}^{\mathrm{d}}}{\mathrm{d} t} \\
& \frac{\mathrm{d} n_{\mathrm{w}}^{\infty}}{\mathrm{d} t}=-n_{\mathrm{g}} \frac{\mathrm{d} n_{\mathrm{w}}^{\mathrm{d}}}{\mathrm{d} t}
\end{aligned}
$$

where $n_{\mathrm{g}}$ is the number of droplets in the crystallizer.

Table 4. Assumptions of homogeneous and rigid models.

\begin{tabular}{ll}
\hline Assumptions of homogeneous model Assumptions of rigid model
\end{tabular}

* The continuous phase is homogeneous.

* The droplet temperature is constant and equal to the temperature of the continuous phase.

* The droplets are spherical.

* The number of droplets is constant.

* The total volume occupied by the system is constant and equal to the sum of component volumes.

* The ketoprofen stays in the droplets.

* Crystallization inside the droplets has been taken into account by a consumption of drug from equilibrium data ${ }^{5}$.

* The dispersed phase is homogeneous.

* The size of droplets are greater than $450 \mu \mathrm{m}$ and constant.

* The solid appears instantaneously in the droplets, at initial time.

* When two liquid phases appear in the droplet, the transfer between the droplets and the continuous phase is made between the organic phase contained into the droplets and the continuous phase. The transfer stops when the organic phase in the droplets runs out.
* The dispersed phase is stagnant. The concentrations of different components depend on the radius.

* The size of droplets is smaller than $450 \mu \mathrm{m}$.

* When two liquid phases appear in the layer at the interface, the solid appears in this layer. 
The changes of acetone and water moles are related to molar fluxes of acetone and water at the interface droplet-continuous phase by the relations:

$$
\begin{aligned}
& \frac{\mathrm{d} n_{\mathrm{a}}^{\mathrm{d}}}{\mathrm{d} t}=-S_{\mathrm{g}}(t) N_{\mathrm{a}}(t) \\
& \frac{\mathrm{d} n_{\mathrm{w}}^{\mathrm{d}}}{\mathrm{d} t}=-S_{\mathrm{g}}(t) N_{\mathrm{w}}(t)
\end{aligned}
$$

where $S_{\mathrm{g}}$ is the external surface of a droplet and $\epsilon^{\text {the }}$ porosity. The porosity is defined as the ratio between the organic liquid phase (acetone + ketoprofen) volume and the total volume of the droplets.

The acetone concentration in the dispersed phase depends on the number and the nature of phases in the droplets. The definition of this concentration is a function of ratio $R_{\mathrm{a}}$ :

- if $R_{\mathrm{a}}(t)>R_{\mathrm{a}, 2}$, then a solid-liquid equilibrium with a high percentage of acetone is obtained:

$$
C_{\mathrm{a}}^{\mathrm{d}, \text { org }}=\frac{n_{\mathrm{a}}^{\mathrm{d}}}{(t) V^{\mathrm{d}}}
$$

if $R_{\mathrm{a}, 1}<R_{\mathrm{a}}(t)<R_{\mathrm{a}, 2}$, then a liquid-liquid-solid equilibrium is reached:

$$
C_{a}^{\mathrm{d}, \text { org }}=\frac{\rho_{2} w_{\mathrm{a}, 2}}{M_{\mathrm{a}}}
$$

- if $R_{\mathrm{a}}(t)<R_{\mathrm{a}, 1}$, then a solid-liquid with a low percentage of acetone is created:

$$
C_{\mathrm{a}}^{\mathrm{d} \text { org }}=0
$$

The acetone concentration in the continuous phase is calculated by the following relation :

$$
C_{\mathrm{a}}^{\infty}=\frac{n_{\mathrm{a}}^{\infty}}{V^{\mathrm{c}}}
$$

The size of droplets remains constant during the process, so the sum of volume fluxes at the interface is zero:

$$
N_{\mathrm{w}}(t)=-N_{\mathrm{a}}(t) \frac{v_{\mathrm{w}}}{v_{\mathrm{e}}}
$$

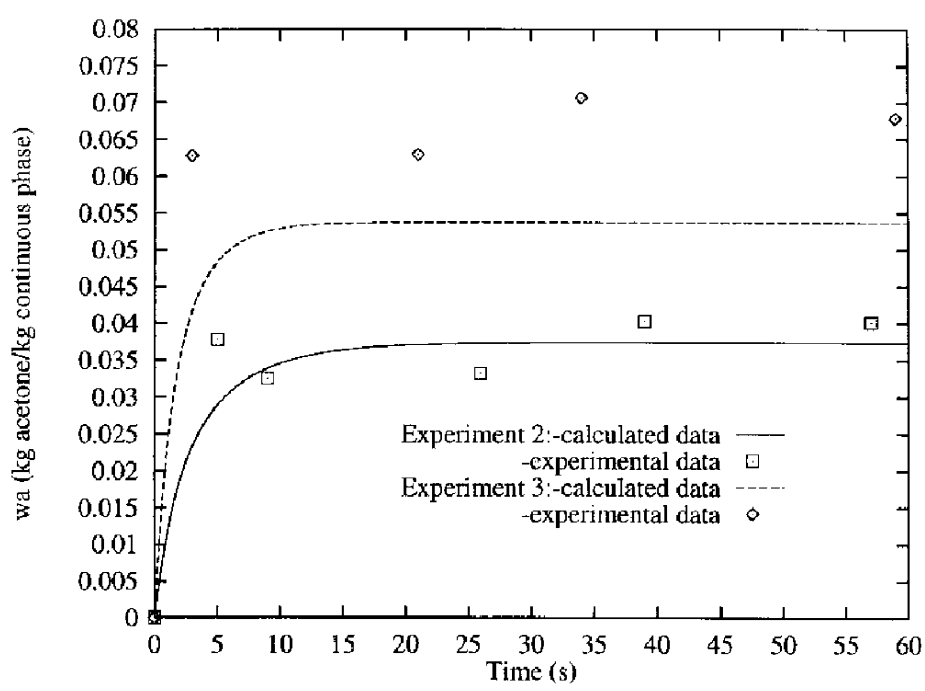

Figure 4. Mass fraction of acetone in the continuousphase: comparison between the experimental and calculated results for experiments 2 and 3 . where $v_{\mathrm{a}}$ and $v_{\mathrm{w}}$ are respectively the molal volumes of acetone and water.

\section{Crystallization:}

Another equation enables us to take into account the crystallization in order to follow the porosity of agglomerates during the transfer:

$$
n_{\mathrm{k}}^{\mathrm{s}}(t)=n_{\mathrm{k}}^{\mathrm{d}}(0)-n_{\mathrm{k}}^{\mathrm{d}}(t)
$$

In the case of solid-liquid equilibium, the number of acetone moles at any moment is :

$$
n_{\mathrm{k}}^{\mathrm{d}}(t)=\frac{w_{\mathrm{k}}^{*} \rho^{\mathrm{m}} V_{\mathrm{d}}(t)}{M_{\mathrm{k}}}
$$

Moreover, if the liquid phase appears, the number of ketoprofen moles at equilibrium is given by:

$$
n_{\mathrm{k}}^{\mathrm{d}}(t)=m_{1} w_{\mathrm{k}, 1}+m_{2} w_{\mathrm{k}, 2}
$$

The number of acetone and ketoprofen moles in the continuous phase are equal to zero and the droplets do not contain water.

$$
\begin{aligned}
t=0 \quad n_{\mathrm{a}}^{\infty} & =0 \\
n_{\mathrm{k}}^{\infty} & =0 \\
\in & =0 \\
n_{\mathrm{e}}^{\mathrm{d}} & =0
\end{aligned}
$$

\section{Resolution Method}

Concentration, volumes and porosity are estimated by finite difference of first order at any moment. The number of created droplets as a function of initial continuous phase temperature $T 2$, initial dispersed phase temperature $T 1$, and initial masses of acetone, water and ketoprofen, is evaluated assuming the additivity of the different components volumes.

The sharp variation of droplet temperature $(T 1 \rightarrow T 2)$ leads to a variation of the dispersed phase density. Assuming the number of droplets is constant, the new volume of droplets is recalculated at the temperature $T 2$. The temperature of the continuous phase determines the value of the particular ratios $R_{\mathrm{a}, 1}$ and $R_{\mathrm{a}, 2}$.

The resolution permits us to follow the liquid volume fraction (liquid phase volume/total volume of the droplets) and the mass fraction of acetone in the continuous phase with time.

\section{Results}

Figure 4 shows the evolution of the acetone mass fraction in the continuous phase for experiments 2 and 3 . The operating conditions of these experiments are reported in Appendix 2. The experimental data appear on this figure. The results seem reasonably good.

\section{Influence of temperature T2:}

The influence of temperature on the shrinkage of 
Table 5. Shrinkage of droplet as a function of the continuous phase.

\begin{tabular}{lc}
\hline $\mathrm{T}\left({ }^{\circ} \mathrm{C}\right)$ & $\mathrm{d}_{\mathrm{g}}$ after shrinkage $(\mu \mathrm{m})$ \\
\hline 50 & 550 \\
0 & 540 \\
20 & 536 \\
10.1 & 534 \\
\hline
\end{tabular}

droplet at initial time has been studied. Table 5 shows the results for initial ratios equal to $0.054 \mathrm{~kg}$ acetone $/ \mathrm{kg}$ water and $1.92 \mathrm{~kg}$ ketoprofen $/ \mathrm{kg}$ acetone. The initial temperature of droplets is $50^{\circ} \mathrm{C}$ and the initial diameter $550 \mu \mathrm{m}$. The shrinkage induced by the difference of temperature is weak: in the range of 3 to $10 \%$.

Figure 5 presents the influence of temperature on the evolution of mass fraction of acetone in the continuous phase. The quantity of acetone transferring into the continuous phase increases as temperature $T 2$ increases because the ratios of the equilibrium ratio $m^{\mathrm{a}}$ and $m^{\mathrm{w}}$ decrease when the temperature increases. So, it seems interesting to carry out the process at high temperature. In Figure 6, porosity is reported as a function of temperature $T 2$. These results do not take into account induction time. Actually, the crystallization of solid can be delayed. The crystallization can be looked upon as instantaneous at 10,20 and $30^{\circ} \mathrm{C}$. In additions the porosity increases and then decreases with time. This initial increase is caused by a partial redissolving of the ketoprofen when the water enters the droplets. Indeed, the solubility of ketoprofen in acetone + water mixture increases when the acetone + water ratio $\left(R_{\mathrm{a}}\right)$ decreases for ratios higher than $0.9 \mathrm{~kg}$ acetone $/ \mathrm{kg}$ water ${ }^{4}$. At $50^{\circ} \mathrm{C}$, the solid crystallizes after two seconds and the porosity decreases rapidly to 0.442 . As the droplets remain liquid for two seconds at $50^{\circ} \mathrm{C}$, the droplets can coalesce in the crystallizer.

\section{MASS TRANSFER MODELLING IN RIGID DROPLETS Equations}

\section{Liquid-liquid system}

The continuity equation for the component $i$ is given by the following relation:

$$
\frac{\partial C_{\mathrm{j}}}{\partial t}+\nabla N_{\mathrm{j}}=0 \quad j=a, w \text { and } k
$$

The mass flux relative to stationary coordinates, assuming constant $C$ and $D_{\mathrm{jm}}$, between the centre of the droplet and the interface, is :

$$
N_{\mathrm{j}}=-C_{\mathrm{j}} D_{\mathrm{j}} \nabla w_{\mathrm{j}}+C_{\mathrm{j}} \overrightarrow{\mathrm{t}}_{\mathrm{i}}
$$

At the interface of the droplet, the flux is written:

$$
N_{\mathrm{j}}^{*}=-C_{\mathrm{j}} D_{\mathrm{jm}} \nabla w_{\mathrm{j}}+C_{\mathrm{j}}\left(\vec{t}_{\mathrm{i}}-\vec{\vartheta}_{\mathrm{s}}\right)
$$

where $t_{s}$ is the velocity of the moving surface.

The balance gives the relation to evaluate the concentrations of acetone and water in the continuous

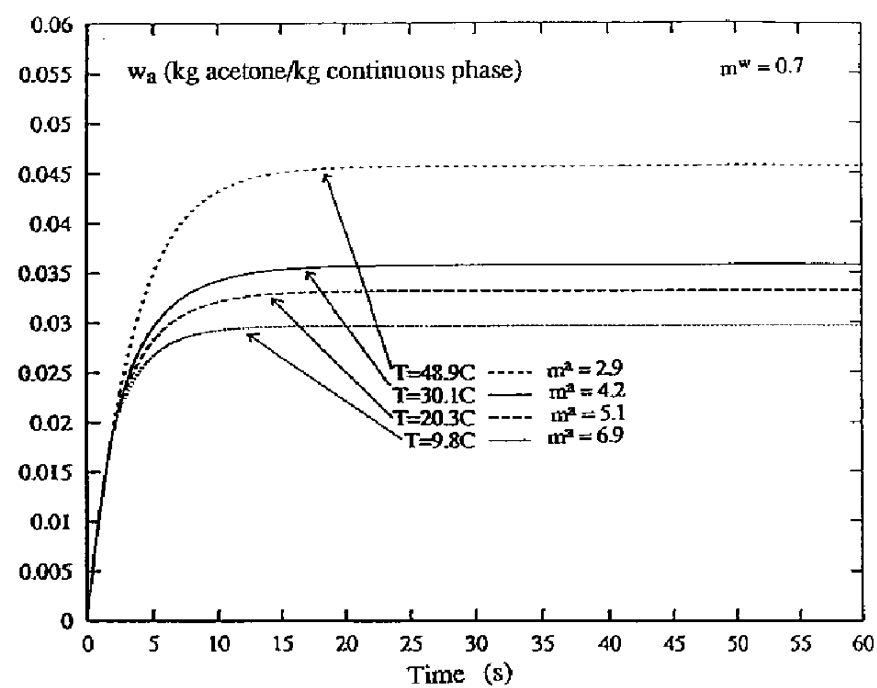

Figure 5. Influence of temperature $T 2$ on the evolution of mass fraction in the continuous phase for a droplet with an initial diameter equal to $550 \mu \mathrm{m}$.

phase:

$$
\begin{aligned}
& \frac{\partial C_{\mathrm{a}}^{\infty}(t)}{\partial t}=\frac{1}{V_{\mathrm{c}}}\left(n_{\mathrm{g}} S_{\mathrm{g}} \dot{N}_{\mathrm{a}}\left(R_{\mathrm{g}}\right)-C_{\mathrm{a}}^{\infty} \frac{\partial V_{\mathrm{c}}}{\partial t}\right) \\
& \frac{\partial C_{\mathrm{w}}^{\infty}(t)}{\partial t}=\frac{1}{V_{\mathrm{c}}}\left(n_{\mathrm{g}} S_{\mathrm{g}} \dot{N}_{\mathrm{w}}\left(R_{\mathrm{g}}\right)-C_{\mathrm{w}}^{\infty} \frac{\partial V_{\mathrm{c}}}{\partial t}\right)
\end{aligned}
$$

The boundary conditions are :

$$
\text { at } r=0 \frac{\partial C_{\mathrm{j}}}{\partial r}=0 \quad j=a, w \text { and } k
$$

\section{Liquid-solid system:}

The crystallization of solid begins in the layer nearest the interface because this corresponds to the layer having the lowest ratio $R_{\mathrm{a}}$. Additional assumptions are:

- Ketoprofen crystallizes instantaneously in the droplet.

- A non porous crust is created in order that the system is in equilibrium.

- After drying, a second crust is formed.

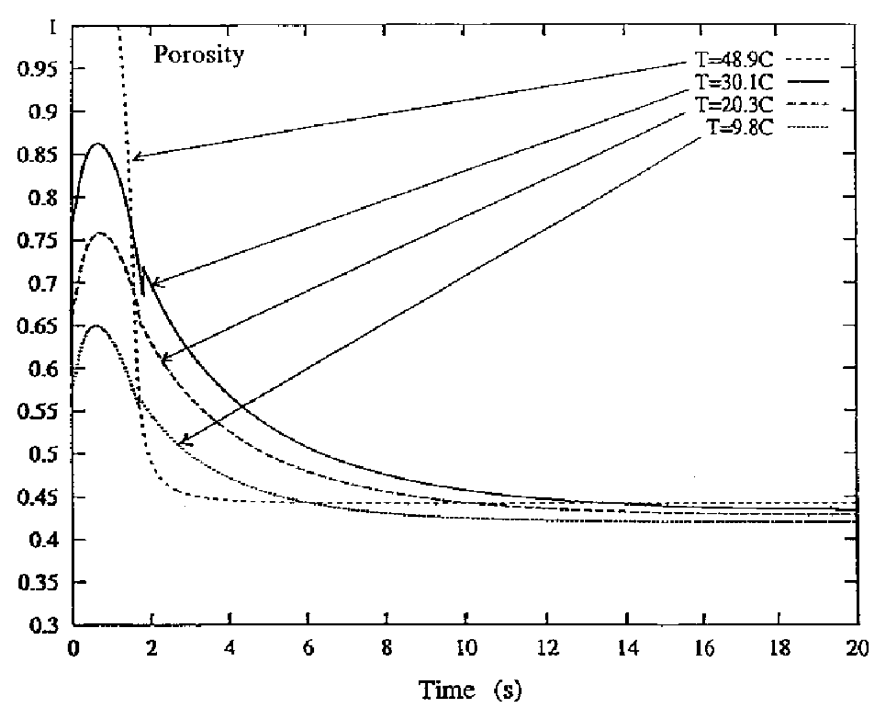

Figure 6. Influence of temperature $T 2$ on the porosity for a droplet with an initial diameter equal to $550 \mu \mathrm{m}$. 
The thickness of these crusts are respectively $e_{\mathrm{c} 1}$ and $e_{\mathrm{c} 2}$. This model gives the thickness of the final crust.

\section{Resolution}

\section{Liquid-liquid system:}

This is a moving boundary problem, so a Lagrangian coordinate has been chosen noted $\xi^{9,10}$. With this coordinate, the continuity equations are written:

$$
\begin{aligned}
\left(\frac{\partial X_{\mathrm{a}}}{\partial t}\right)_{\xi}= & \frac{1}{\xi^{2}} \frac{\partial}{\partial \xi}\left\{\left(\frac{C_{\mathrm{k}}}{C_{\mathrm{k}}^{0}}\right)^{2} \frac{r^{4}}{\xi^{2}}\right. \\
& {\left.\left[D_{\mathrm{am}} \frac{\partial X_{\mathrm{a}}}{\partial \xi}+\frac{X_{\mathrm{a}}}{x_{\mathrm{k}}}\left(D_{\mathrm{wm}}-D_{\mathrm{am}}\right) \frac{\partial x_{\mathrm{w}}}{\partial \xi}\right]\right\} } \\
\left(\frac{\partial X_{\mathrm{w}}}{\partial t}\right)_{\xi}= & \frac{1}{\xi^{2}} \frac{\partial}{\partial \xi}\left\{\left(\frac{C_{\mathrm{k}}}{C_{\mathrm{k}}^{0}}\right)^{2} \frac{r^{4}}{\xi^{2}}\right. \\
& {\left.\left[D_{\mathrm{wm}} \frac{\partial X_{\mathrm{w}}}{\partial \xi}+\frac{X_{\mathrm{w}}}{x_{\mathrm{k}}}\left(D_{\mathrm{am}}-D_{\mathrm{wm}}\right) \frac{\partial x_{\mathrm{a}}}{\partial \xi}\right]\right\} }
\end{aligned}
$$

where $X_{\mathrm{a}}$ and $X_{\mathrm{w}}$ are respectively the ratios between the mass fractions of acetone and ketoprofen and the ratio between the mass fractions of water and ketoprofen. The corresponding boundary conditions are:

$$
\begin{aligned}
& \left(\frac{\partial X_{\mathrm{a}}}{\partial \xi}\right)_{\xi=0}=0 \\
& \left(\frac{\partial X_{\mathrm{w}}}{\partial \xi}\right)_{\xi=0}=0
\end{aligned}
$$

The corresponding interfacial fluxes can be written :

$$
\begin{aligned}
J_{\mathrm{a}} & =\left(\frac{k_{\mathrm{a}}\left(C_{\mathrm{d}}^{\mathrm{a}}\left(R_{\mathrm{g}}\right)-m^{\mathrm{a}} C_{\infty}^{\mathrm{a}}\right)+x_{\mathrm{a}} J_{\mathrm{w}}}{\left(1-x_{\mathrm{a}}\left(R_{\mathrm{g}}\right)\right)}\right) \\
J_{\mathrm{w}} & =\left(\frac{k_{\mathrm{w}}\left(C_{\mathrm{d}}^{\mathrm{w}}\left(R_{\mathrm{g}}\right)-m^{\mathrm{w}} C_{\infty}^{\mathrm{w}}\right)+x_{\mathrm{w}} J_{\mathrm{a}}}{\left(1-x_{\mathrm{w}}\left(R_{\mathrm{g}}\right)\right)}\right)
\end{aligned}
$$

The number of droplets created is calculated by the method used in the first model assuming the additivity of different component volumes. The droplets is divided into 50 layers. The differential second order terms with respect to space have been approximated by finite differences $\left(2^{\text {nd }}\right.$ order). Derivatives with respect to time have been integrated by the Runge Kutta Merson method ( $4^{\text {th }}$ order). The numerical resolution permits us to evaluate the radius of the droplet when the ratio $R_{\mathrm{a}}$ is lower than $R_{a}^{2}$, the mass fraction of acetone in the continuous phase and the mass fractions of different components into the droplet as functions of time and radius.

\section{Liquid-solid system:}

Knowing the different concentrations of components in the droplet as a function of the radius, the mass (and then the volume) of ketoprofen that crystallizes has been calculated in order to bring the system in the droplet to equilibrium. This volume permits evaluation of the thickness of the first crust formed. After drying, the

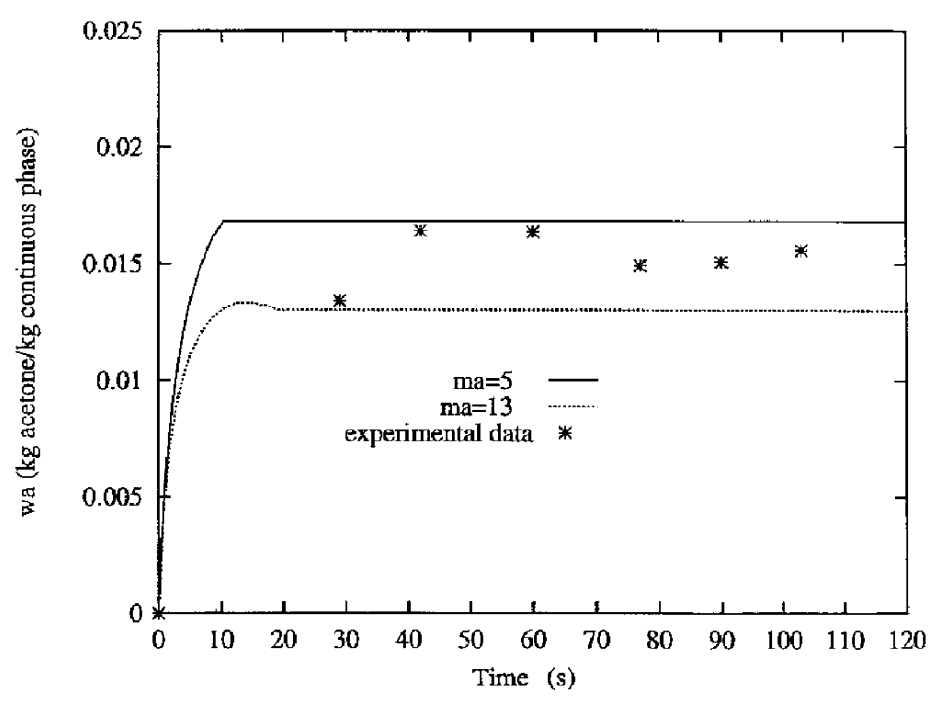

Figure 7. Mass fraction of acetone in the continuousphase: comparison between the experimental and calculated data for a droplet with an initial diameter equal to $200 \mu \mathrm{m}$, for two ratios $m^{\mathrm{a}}$.

thickness of the second crust is estimated by assuming that all solvants (acetone and water) are evaporated and that all solid crystallizes into the grains in order to grow the first crust.

The resolution allows one to follow the radius and the mass fraction of acetone in the continuous phase with time.

\section{Results}

Calculations have been made with droplets having a diameter to $200 \mu \mathrm{m}$. The initial mass ratios, ketoprofen/ acetone and acetone/water are respectively $1.88 \mathrm{~kg}$ ketoprofen $/ \mathrm{kg}$ acetone and to $0.024 \mathrm{~kg}$ acetone $/ \mathrm{kg}$ water.

Evolution of acetone mass fraction in the continuous phase obtained at $20^{\circ} \mathrm{C}$ is reported in Figure 7. The trends of the calculated $\left(m^{\mathrm{a}}=13\right)$ and experimental curves are similar. The results obtained with $\left(m^{\mathrm{a}}=5\right)$ are also presented. The ratio $m^{\text {a }}$ influences the simulation and the assumptions made to calculate $m^{\text {a }}$ may explain this influence. The concentration inside the droplet is taken to be homogeneous and similar in the whole volume of the droplet. But the presence of the crust modifies this concentration and this ratio. The discontinuity observed on the curve corresponding to $m^{\mathrm{a}}$ equal to 5 , is caused by the stopping of transfers and crystallization.

\section{Influence of temperature T2:}

The temperature of the continuous phase has an influence on the thickness of the crust before and after drying. In Table 6 , the results concerning this influence are reported. The thickness of the first crust increases as the temperature decreases. This results from the decrease of ketoprofen solubility when temperature decreases. Figures 8 and 9 show respectively the acetone weight fraction in the continuous phase and the droplet radius as a function of time and temperature $T 2$. When $T 2$ increases, the droplet radius decreases faster. As the ratio $m^{\text {a }}$ decreases when $T 2$ increases (Table 3), the mass of transfered acetone is higher at $50^{\circ} \mathrm{C}$ than at $10^{\circ} \mathrm{C}$. So, the droplet radius decreases more rapidly at $50^{\circ} \mathrm{C}$ than at $10^{\circ} \mathrm{C}, m^{\mathrm{w}}$ remaining quasi-constant. As the initial mass 
Table 6 : Influence of droplet temperature $T 1$ on the thicknesses of the two crusts, with an initial radius equal to $100 \mu \mathrm{m}$.

\begin{tabular}{lccc}
\hline $\begin{array}{l}\text { Temperature of } \\
\text { droplet, } T 1\left({ }^{\circ} \mathrm{C}\right)\end{array}$ & $\begin{array}{c}\text { Radius before } \\
\text { crystallization }(\mu \mathrm{m})\end{array}$ & $\begin{array}{l}\text { Thickness of the crust } \\
\text { before drying, } e_{\mathrm{c} 1}(\mu \mathrm{m})\end{array}$ & $\begin{array}{c}\text { Thickness of the crust } \\
\text { after drying, } e_{\mathrm{c} 2}(\mu \mathrm{m})\end{array}$ \\
\hline 10 & 99.4 & 14.8 & 24.8 \\
20 & 94.1 & 14.9 & 29.5 \\
30 & 93.6 & 12.6 & 29.9 \\
50 & 91.7 & 8.2 & 31.8 \\
\hline
\end{tabular}

of ketoprofen within the droplets is the same at 10 and $50^{\circ} \mathrm{C}$, with an identical initial radius, the thickness of the crust formed by drying will be higher at $50^{\circ} \mathrm{C}$ than at $10^{\circ} \mathrm{C}$ because the final radius is smaller.

\section{CONCLUSION}

The different phenomena (heat transfer, mass transfer and hydrodynamics) occurring in the quasi-emulsion process have been studied in order to control the size and the internal structure of grains formed. Prediction of the internal structures of grains which have been obtained by the quasi-emulsion process depends on the initial size of droplets formed.

Initial study of these distinct phenomena has shown that mass transfer has a controlling effect. Heat transfer in a stagnant continuous phase maintained at a constant temperature is almost instantaneous and the internal droplet circulation influences the final internal structure. This study has permitted us to deduce from the terminal velocity a limiting size equal to $450 \mu \mathrm{m}$. It has then been assumed that internal circulation hardly occurs in the droplets being initially smaller than this limiting size. From this limiting size, two boundary cases have been modelled according to the initial size of the droplet:

- droplets with homogeneous concentrations leading to spherical grains with a full internal structure: the homogeneous droplet model

rigid droplets leading to spherical grains with crusts: the rigid droplet model.

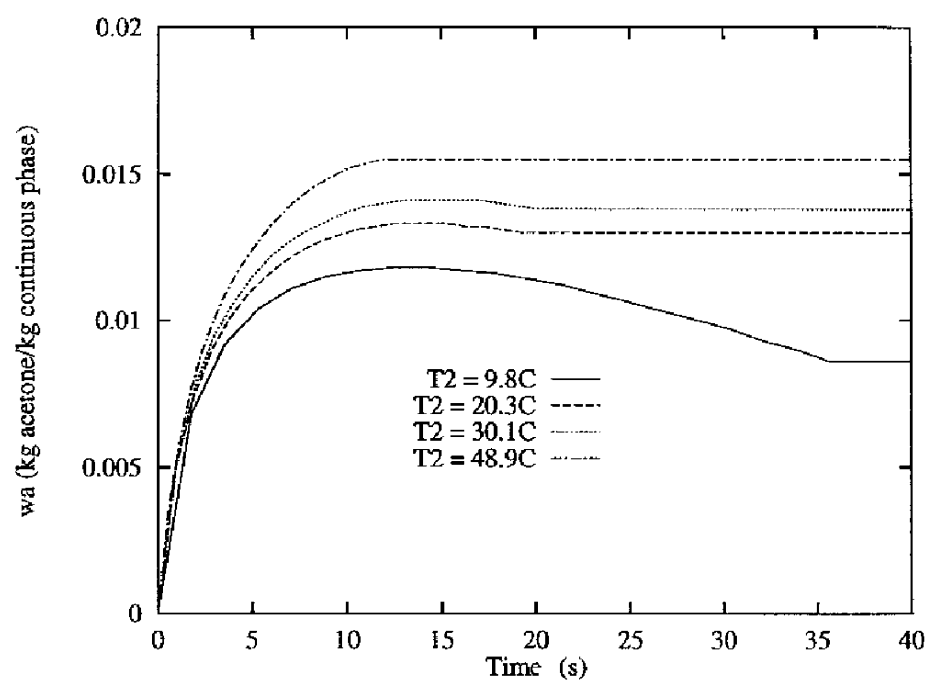

Figure 8. Influence of temperature $T 2$ on the evolution of mass fraction in the continuous phase for a droplet with an initial diameter equal to $200 \mu \mathrm{m}$.
These two models lead to the creation of supersaturation rates in the droplets and allow the study of the influence of continuous phase temperature on the transfer of solvents.

For a given initial size, the homogeneous droplet model leads to the calculation of the variation of grain porosity with time, whereas the rigid droplet model enables us to predict the final radius and the final thickness of a non porous crust.

Control of the initial size of the droplets may allow the control of the final size, and of the internal structure of grains, and, knowing the equilibrium states, the scale-up of the process.

\section{APPENDIX 1}

\section{Diffusion coefficient of acetone in acetone+ ketoprofen mixture, $D_{\mathrm{am}}$ :}

The diffusion coefficient at infinite dilution $D_{k a}^{\infty}$ has been calculated by the Reddy and Doraiswamy equation. The molar volumes to the normal boiling point are obtained by the additivity of the Lebasmolar volume of atoms or groups of atoms ${ }^{11}$. They are equal to $74 \times 10^{-6} \mathrm{~m}^{3} \mathrm{~mol}^{-1}$ and $320 \times 10^{-6} \mathrm{~m}^{3} \mathrm{~mol}^{-1}$ respectively. The value of the diffusion coefficient is $2.49 \times 10^{-9} \mathrm{~m}^{2} \mathrm{~s}^{-1}$ at $20^{\circ} \mathrm{C}$. The diffusion coefficient of ketoprofen in the binary system (acetone + ketoprofen) has been calculated from the empiric Gordon equation established in the case of an electrolytic solution ${ }^{11}$. This equation has been transformed

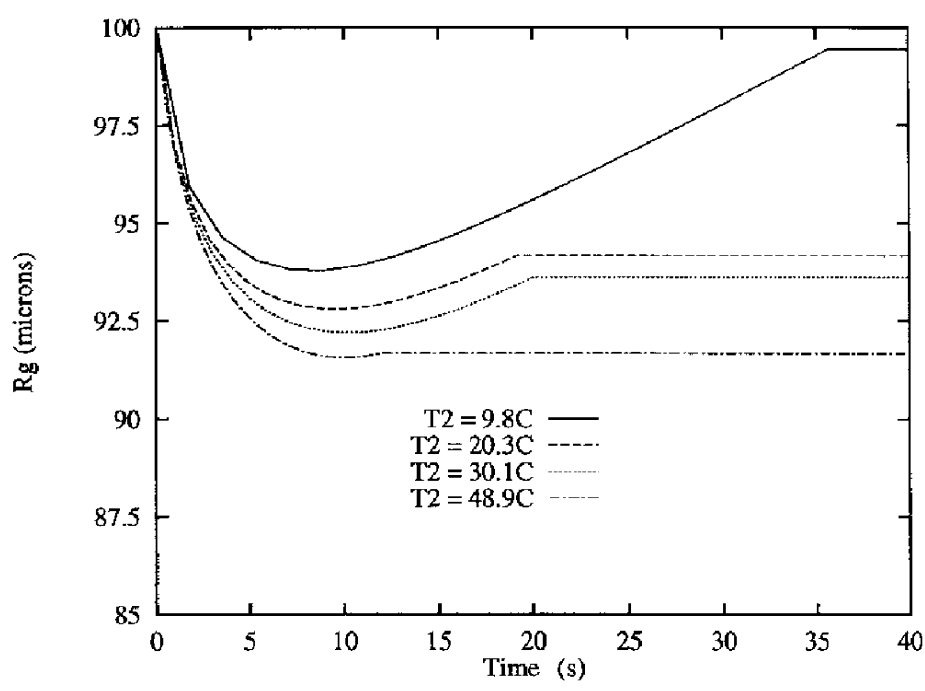

Figure 9. Influence of temperature $T 2$ on the evolution of a radius for a droplet with an initial diameter equal to $200 \mu \mathrm{m}$. 
into the following equation:

$$
D_{\mathrm{ka}}=D_{\mathrm{ka}}^{\infty} \frac{\mu_{\text {solv }}}{\mu} \frac{V}{n_{\text {solv }} V_{\text {solv }}}\left(1+x_{\mathrm{k}} \frac{\partial \ln \gamma_{\mathrm{k}}}{\partial x_{\mathrm{k}}}\right)
$$

The volume of solution, $V$, is calculated by assuming the additivity of acetone and ketoprofen volumes.

This equation needs the viscosity of acetone + ketoprofen mixtures as a function of the concentration of ketoprofen in the mixture and the temperature. The viscosities of these solutions with concentrations lower then $0.653 \mathrm{~kg}$ ketoprofen $/ \mathrm{kg}$ solution have been measured from terminal velocity of a falling sphere $^{12}$ at $20^{\circ} \mathrm{C}$. The data have been correlated by the following equation :

$$
\mu_{\mathrm{ak}}(\mathrm{Pas})=0.46 \times 10^{\left(-3+3.38 w_{\mathrm{k}}^{2}\right)}
$$

with a coefficient of correlation equal to 0.98 .

When the weight fraction of ketoprofen tends toward 1 , the viscosity of solution tends toward 1.1 Pa s.

The activity coefficient of ketoprofen in acetone+ ketoprofen solution is calculated by the UNIQUAC model ${ }^{4}$. The derivative of this coefficient, $\frac{\partial \ln y_{k}}{\partial x_{k}}$, is evaluated by finite differences of $2^{\text {nd }}$ order. The value of $\frac{\partial \ln y}{\partial x_{k}}$, corresponding to a concentration of $0.651 \mathrm{~kg}$ ketónrofen $/ \mathrm{kg}$ solution is 1.108 . The calculated diffusion coefficient is $1.9 \times 10^{-10} \mathrm{~m}^{2} \mathrm{~s}^{-1}$.

\section{Diffusion coefficient of water in acetone + ketoprofen mixture, $D_{\mathrm{em}}$ :}

This diffusion coefficient has been calculated for dilute mixtures of acetone + ketoprofen $\left(x_{\mathrm{w}} \rightarrow 0\right)$ from the diffusion coefficients of water in acetone and water in ketoprofen at infinite dilution. The first coefficient has been valued at $5.28 \times 10^{-9} \mathrm{~m}^{2} \mathrm{~s}^{-1}$ for a temperature equal to $20^{\circ} \mathrm{C}$ by the Reddy and Doraiswamy equation. The second coefficient is calculated from the modified equation for electrolytic solution at the same temperature. The viscosity of solution, i.e. solution water + ketoprofen concentrated with ketoprofen, has been assumed equal to $1.1 \mathrm{Pas}$ and the diffusion coefficient of ketoprofen in water, calculated by the Reddy and Doraiswamy equation is equal to $7.4 \times 10^{-10}$ $\mathrm{m}^{2} \mathrm{~s}^{-1}$ when the molar fraction of ketoprofen tends towards 1. The diffusion coefficient of water in acetone + ketoprofen at $20^{\circ} \mathrm{C}$ is estimated to $1.83 \times 10^{-9} \mathrm{~m}^{2} \mathrm{~s}^{-1}$. The activity coefficient and the derivative of this coefficient have calculated by the same method used for the diffusion coefficient of acetone in acetone + ketoprofen mixture.

\section{NOMENCLATURE}

$c_{\mathrm{p}}^{\mathrm{m}} \quad$ heat capacity of mixture, $\mathrm{J} \mathrm{mol}^{-1{ }^{\circ}} \mathrm{C}^{-1}$

$C_{\mathrm{i}}$ molar concentration of species i, mole $\mathrm{m}^{-3}$ or $\mathrm{kg} \mathrm{m}^{-3}$

$d_{\mathrm{g}} \quad$ diameter of droplet, $\mathrm{m}$

$D_{\mathrm{ij}} \quad$ diffusion coefficient of component $i$ in component $j, \mathrm{~m}^{2} \mathrm{~s}^{-1}$

$\mathrm{D}_{\mathrm{ij}}^{\mathrm{i}}$ diffusion coefficient of component $i$ in component $j$ at infinite dilution, $\mathrm{m}^{2} \mathrm{~s}^{-1}$

$e_{\mathrm{c} 1} \quad$ thickness of first crust, $\mathrm{m}$

$e_{\mathrm{c} 2}$ thickness of first crust, $m$

$e^{\text {film }}$ thickness of the emulsifier layer, $m$

$g$ gravitationalacceleration, $\mathrm{m}^{2} \mathrm{~s}^{-1}$

$k_{\mathrm{j}} \quad$ mass transfer coefficient, $\mathrm{m} \mathrm{s}^{-1}$

$m^{j} \quad$ ratio between the equlibrium ratio, $\kappa_{j}^{1}$ and $\kappa_{j}^{2}$

$m_{1} \quad$ weight of aqueous phase in the liquid-liquid equilibrium, $\mathrm{kg}$

$m_{2}$ weight of organic phase in the liquid-liquid equilibrium, $\mathrm{kg}$

$M \quad$ molecular weight, $\mathrm{kg} \mathrm{mole}^{-1}$

$n$ mole number

$n_{\mathrm{g}} \quad$ number of droplets

$N_{\mathrm{i}} \quad$ flux of species $i$ in a stationary coordinate frame of reference, $\mathrm{kg}$ $\mathrm{m}^{-2} \mathrm{~s}^{-1}$ or mole $\mathrm{m}^{-2} \mathrm{~s}^{-1}$

$r \quad$ radius coordinate, $\mathrm{m}$

$R_{\mathrm{a}} \quad$ acetone mass ratio in acetone + water mixture, $\mathrm{kg}$ acetone $/ \mathrm{kg}$ acetone+ water

$R_{\mathrm{a}, 1} \quad$ particular ratio, $\mathrm{kg}$ acetone/kg acetone + water

$R_{\mathrm{a}, 2}$ particular ratio, $\mathrm{kg}$ acetone/kg acetone + water

$R_{\mathrm{g}} \quad$ radius of droplet, $\mathrm{m}$

$R_{\mathrm{i}} \quad$ rate of production or consumption of $i$ due to crystallization in the droplet, mole $\mathrm{m}^{-3} \mathrm{~s}^{-1}$

$S_{\mathrm{g}} \quad$ surface of droplet, $\mathrm{m}^{2}$

$t$ time, $\mathrm{s}$

$T$ temperature, ${ }^{\circ} \mathrm{C}$ or $\mathrm{K}$

$T 1$ initial temperature of organic solution, ${ }^{\circ} \mathrm{C}$ or $\mathrm{K}$

$T 2$ initial temperature of aqueous solution, ${ }^{\circ} \mathrm{C}$ or $\mathrm{K}$

$U^{\infty} \quad$ terminal velocity, $\mathrm{m} \mathrm{s}^{-1}$

$v$ molal volume, $\mathrm{m}^{3} \mathrm{~mole}^{-1}$

$V \quad$ volume, $\mathrm{m}^{3}$

$x_{\mathrm{i}} \quad$ molar fraction of component $i$

$w_{\mathrm{i}} \quad$ weight fraction of component $i$

\section{Greek letters}

$\alpha^{\mathrm{m}} \quad$ thermal diffusivity of acetone + ketoprofen mixture, $\mathrm{m}^{2} \mathrm{~s}^{-1} \delta T$ thermal penetration distance, $\mathrm{m}$

$\Delta \rho \quad$ difference between the density of mixture acetone+ ketoprofen and the density of aqueous phase, $\mathrm{kgm}^{3}$

$\epsilon$ porosity

$\stackrel{E}{\mathrm{i}}_{\mathrm{i}} \quad$ activity coefficient of component $i$

$\kappa \quad$ ratio between the viscosity of the droplet (acetone+ ketoprofen mixture) and the viscosity of the aqueous phase

$\kappa_{\mathrm{j}}^{1} \quad$ equilibrium ratios between the dispersed phase and the

emulsifier

$\kappa_{\mathrm{j}}^{2} \quad$ equilibriumratios between the emulsifier and the continuous phase

$\mu \quad$ viscosity, Pa s

$\rho \quad$ density of acetone + ketoprofen mixture, $\mathrm{kgm}^{-3}$

$\rho^{\mathrm{m}} \quad$ density of acetone + ketoprofen mixture, $\mathrm{kgm}^{-3}$

$\sigma \quad$ relative supersaturation

$$
\left(=\frac{C_{\mathrm{i}}-C_{\mathrm{i}}^{*}}{C_{\mathrm{i}}^{*}}\right)
$$

$\xi \quad$ Lagrangian coordinate

\begin{tabular}{|c|c|c|c|c|c|c|c|}
\hline experiment & $\begin{array}{c}W_{\mathrm{k}} \\
\text { (kg ketoprofen } \\
\text { / kg acetone) }\end{array}$ & $\begin{array}{c}W_{\mathrm{e}} \times 10^{6} \\
\text { (kg emulsifier } \\
/ \mathrm{kg} \text { water) }\end{array}$ & $\begin{array}{c}R_{\mathrm{a}} \\
\text { (kg acetone } \\
\text { / kg water) }\end{array}$ & $\begin{array}{l}\Delta T \\
\left({ }^{\circ} \mathrm{C}\right)\end{array}$ & $\begin{array}{c}v_{\mathrm{c}} \times 10^{6} \\
\left(\mathrm{~m}^{3} / \mathrm{s}\right)\end{array}$ & $\begin{array}{c}N \\
\text { (rpm) }\end{array}$ & $\begin{array}{c}\text { Puissanœe dissipée } \\
P_{\mathrm{s}}^{*} \times 10^{2} \\
(\mathrm{~W} / \mathrm{kg} \text { suspension })\end{array}$ \\
\hline 1 & 1.73 & 223 & 0.026 & 29.4 & 1.3 & 516 & 8.7 \\
\hline 2 & 1.94 & 225 & 0.054 & 27.1 & 3.0 & 450 & 7.3 \\
\hline 3 & 1.92 & 225 & 0.078 & 27.7 & 2.7 & 416 & 8.7 \\
\hline 4 & 1.01 & 239 & 0.028 & 27.7 & 3.5 & 516 & 8.9 \\
\hline 5 & 1.88 & 227 & 0.024 & 38.4 & 2.2 & 516 & 8.7 \\
\hline 6 & 1.96 & 161 & 0.023 & 0.9 & 1.5 & 516 & 8.7 \\
\hline
\end{tabular}

\section{APPENDIX 2}

Operating conditions of experiments 


\section{Subscripts}

aq aqueous phase in the liquid-liquid equilibrium

c continuous phase

d dipersed phase

film layer of emulsifier

$\mathrm{m}$ mixture

org organic phase in the liquid-liquid equilibrium

s solid

solv : solvent

$\infty \quad$ continuous phase

* this symbol characterizes the equilibrium

1 aqueous phase in the liquid-liquid equilibrium

2 organic phase in the liquid-liquid equilibrium

\section{Superscripts}

a acetone

$\mathrm{k} \quad$ ketoprofen

w water

0 initial

\section{REFERENCES}

1. Sano, A., Kuriki, T., Kawashima, Y., Takeuchi, H., Hino, T. and Niwa, T., 1989, Particle design of tolbutamide by the spherical crystallization technique. II. Factors causing polymorphism of tolbutamide spherical agglomerates, Chem Pharm Bull 37(8): 2183-2187.

2. Kawashima, Y., 1994, New processes. Application of spherical crystallization to particulate design of pharmaceuticals for direct tabletting and coating and new drug delivery system, in: Powder Technology and Pharmaceutical Processes, Chapter 14, part 1, 493-511, Ed. Chulia, D., Deleuil, M. and Pourcelot, Y. (Elsevier Science B.V., Amsterdam, The Netherlands)

3. Espitalier, F., 1994, Procédé discontinu de cristallisation d'un principeactif pharmaceutiquepar le mécanisme de quasi-émulsion, PhD Thesis, (INP Toulouse, France).

4. Espitalier, F., Biscans B., Sere Peyrigain P. and Laguerie C., 1995, Ternary diagram : alpha-(3-benzoylpheny)-propionic acid (ketoprofen) in acid-water mixtures at different temperatures. Experimental data and predicted results, Fluid Phase Eq., 113: 151-171.
5. Espitalier,F., Biscans, B., Authelin, J. R., Deleuil, M., Laguerie, C. Crystallization of an active substance from emulsion droplets. Interactions between usage properties and process. in: Industrial Crystallization 93, vol. 1, p 3-025-3-030. Ed. by Z. H. Rohkowski, Warsaw.

6. Clift, R., Grace, J. R. and Weber, M. E., 1978, Bubbles, drops and particles, in: Bubbles, Drops and Particles, (Academic Press, New York, U.S.A)

7. Bird, R. B., Steward, W. E. and Lightfoot, E. N., 1960, Transport Phenomena, (Wiley Int., New York, USA).

8. Espitalier,F., Biscans, B. and Laguerie, C., Cristallisationélaborée pour la production d'agglomérats sphériques à propriétés controlées. 1994, Proc Colloque Science et Technologie des Poudres, Lyon 1: pp CO 1.1-CO1.4.

9. Raoult-Wack, 1991, Les procédés de déshydration-imprégnation par immersion dans des solutions concentrées (DII). Etude expérimentale et modélisation des transferts d'eau et de soluté sur gel modèle, PhD Thesis, (University of Montpellier II, Sciences and Technics of Languedoc, France).

10. Zagrouba, 1993, Séchage mixte par convection et un apport rayonnant micro-onde des milieux déformables. Modélisation des phénomènes de transfert de chaleur et de matière., PhD Thesis, (INP de Lorraine, France).

11. Sherwood, T. K., Pigford, R. L. and Wilke, C. R., 1975, Mass transfer, (Mac Graw-Hill Book Co, New York, USA).

12. Espitalier, F., Biscans, B., and LaguerieC., 1995, Some physicaldata on ketoprofen in solutions, Chem Eng Data J, 40 (6): 1222-1224.

\section{ACKNOWLEDGEMENTS}

The authors wish to acknowledge Rhône-Poulenc-Rorer Company, and the French Ministère de l'Enseignement Supérieur et de la Rcherche (MESR) for their financial support for this project.

\section{ADDRESS}

Correspondenceconcerningthis paper should be addressed to Dr F. Espitalier, Laboratoire de Génie Chimique UMR CNRS 5503, ENSI GC, 18 chemin de la Loge 31078 Toulouse, France. 